Corrigendum

\title{
Corrigendum to "WS-5 Extract of Curcuma longa, Chaenomeles sinensis, and Zingiber officinale Contains Anti-AChE Compounds and Improves $\beta$-Amyloid-Induced Memory Impairment in Mice"
}

\author{
Ju Eun Kim, ${ }^{1}$ Abinash Chandra Shrestha, ${ }^{1}$ Hyo Shin Kim, ${ }^{1}$ Ha Neul Ham, ${ }^{1}$ Jun Hyeong Kim, ${ }^{1}$ \\ Yeong Jee Kim, ${ }^{1}$ Yun Jeong Noh, ${ }^{1}$ Su Jin Kim, ${ }^{1}$ Dae Keun Kim, ${ }^{1}$ Hyung Kwon Jo, ${ }^{2}$ \\ Dae Sung Kim, ${ }^{2}$ Moon Kwang Hyun, ${ }^{3}$ Jeong Ho Lee, ${ }^{3}$ Kyung Ok Jeong, ${ }^{3}$ \\ and Jae Yoon Leem (iD) \\ ${ }^{1}$ College of Pharmacy, Woosuk University, Wanju, Jeonbuk 55338, Republic of Korea \\ ${ }^{2}$ Hanpoong Pharm. Co., Ltd., Wanju, Jeonbuk 55336, Republic of Korea \\ ${ }^{3}$ Sunchang Institute of Health and Longevity, Sunchang, Jeonbuk 56015, Republic of Korea \\ Correspondence should be addressed to Jae Yoon Leem; jyleem@woosuk.ac.kr
}

Received 5 November 2020; Accepted 5 November 2020; Published 11 August 2021

Copyright (C) 2021 Ju Eun Kim et al. This is an open access article distributed under the Creative Commons Attribution License, which permits unrestricted use, distribution, and reproduction in any medium, provided the original work is properly cited.

In the article titled "WS-5 Extract of Curcuma longa, Chaenomeles sinensis, and Zingiber officinale Contains Anti-AChE Compounds and Improves $\beta$-Amyloid-Induced Memory Impairment in Mice" [1], there was an error in Figure 4(a), where "DPPH inhibition activity (\% of control)" should be corrected to "DPPH radical level (\% of control)."

In addition, the authors wish to replace Figure 15 to show a modified possible underlying mechanism for WS-5.

The corrected Figures 4 and 15 are shown as follows.

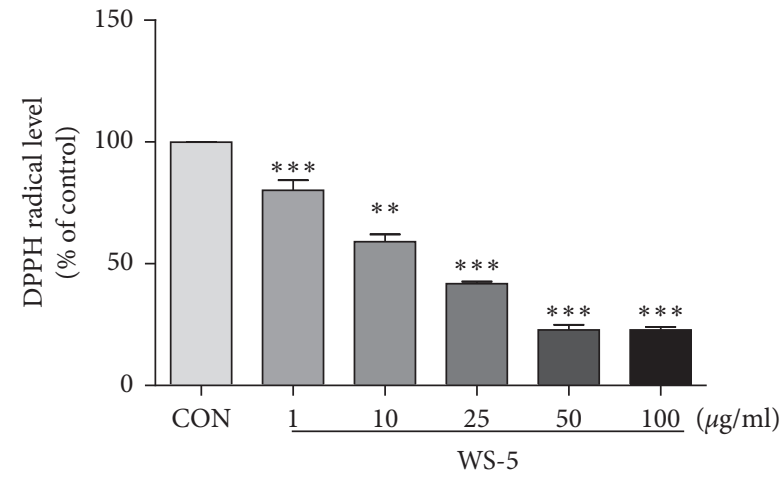

(a)

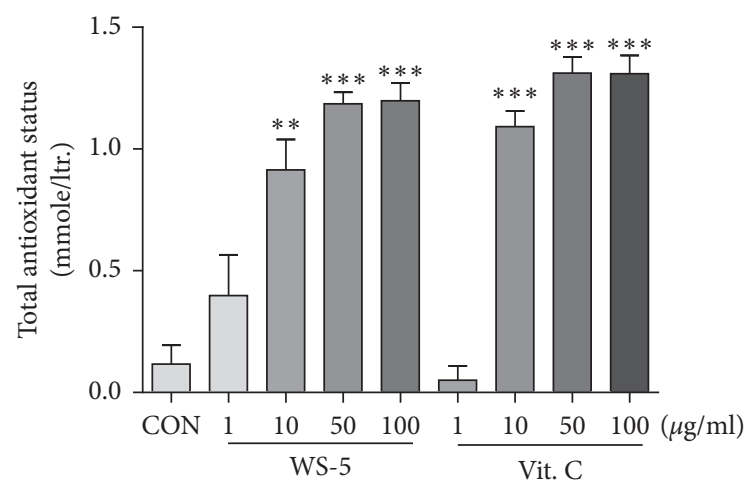

(b)

FIGURE 4: DPPH radical scavenging activity and TAS of WS-5. Inhibition of DPPH was measured using the radical scavenging assay (a), with vitamin $\mathrm{C}$ as positive control, along with the TAS assay (b). Results are expressed as the means \pm SEM of three independent experiments $\left({ }^{*} p<0.05,{ }^{* *} p<0.01,{ }^{* * *} p<0.001\right.$ vs. control). 

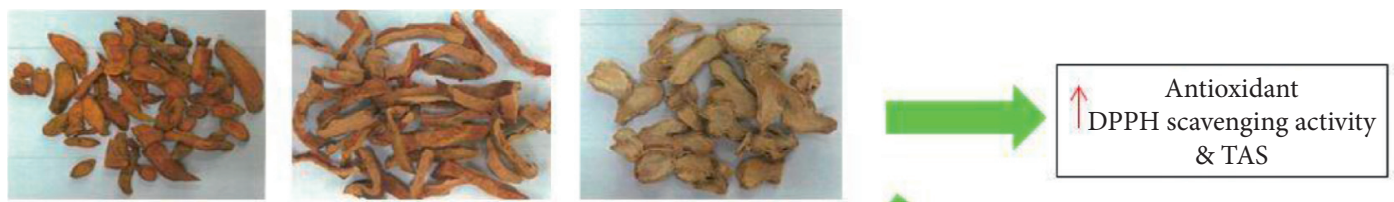

Curcuma longa rhizone Chaenomeles sinensis fruit Zingiber officinale rhizone WS-5
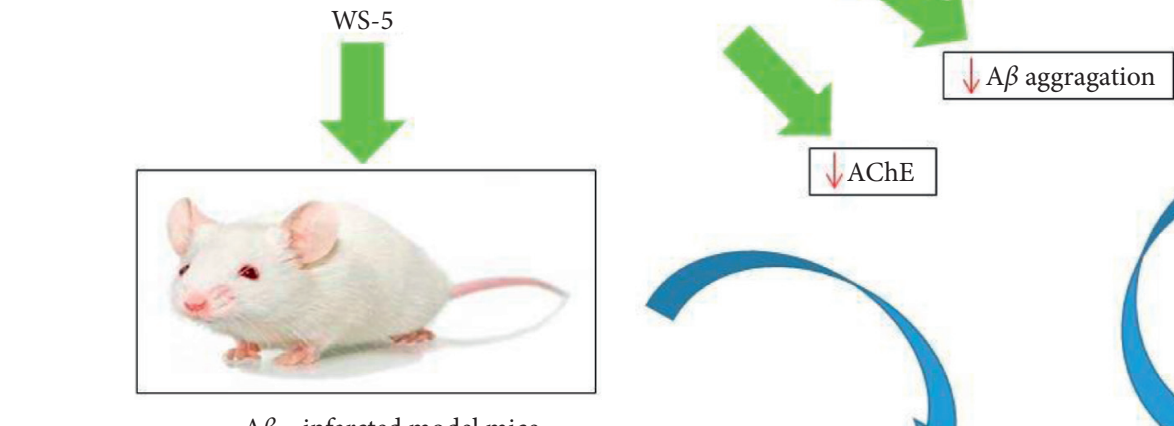
$\downarrow N O$ $\downarrow$ Cytokine level (TNF- $\alpha$ \& IL-6)

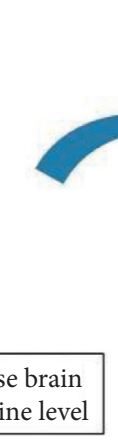

$\downarrow \mathrm{A} \beta$ secretion

$\mathrm{A} \beta_{42}$ infarcted model mice

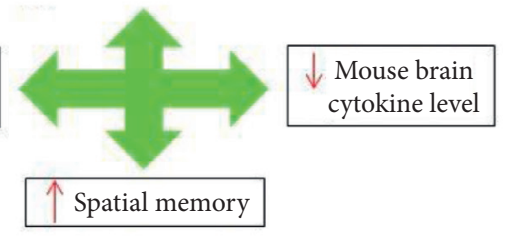

$\downarrow \mathrm{AChE}$
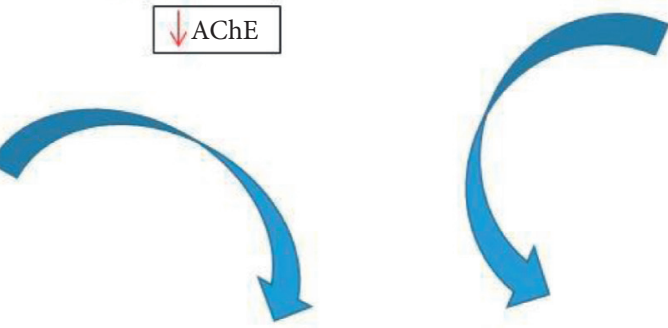

Improve memory function

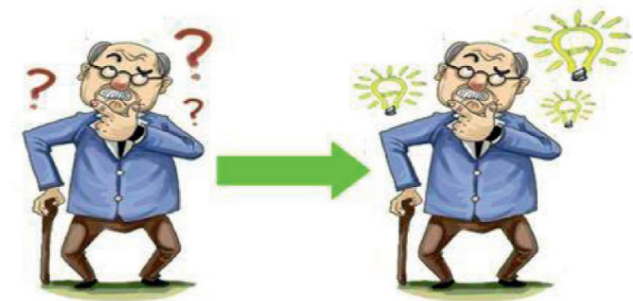

Figure 15: Schematic diagram showing possible underlying mechanism of WS-5.

\section{References}

[1] J. E. Kim, A. C. Shrestha, H. S. Kim et al., "WS-5 extract of Curcuma longa, Chaenomeles sinensis, and Zingiber officinale contains anti-ACHE compounds and improves $\beta$-amyloidinduced memory impairment in mice," Evidence-Based Complementary and Alternative Medicine, vol. 2019, Article ID 5160293, 16 pages, 2019. 